\title{
O Comércio de Escravos na Obra de Antônio de Oliveira de Cadornega
}

Gitibá Faustino

Entre os séculos XVI e XVIII, o expansionismo colonial e comercial português desenvolveu-se sobretudo através da rota Brasil-África. A implantação da agricultura tropical foi a estratégia utilizada pelos portugueses para ocuparem e colonizarem os territórios luso-americanos.

A colonização representou uma nova etapa no desenvolvimento da economia européia porque "se insere no processo de superação das barreiras que se antepuseram, no fim da Idade Média, ao desenvolvimento da economia mercantil, e ao fortalecimento das camadas urbanas e burguesa". ${ }^{1}$ Se as relações comerciais com outros continentes (Ásia e África) se efetuaram predominantemente na esfera da circulação de mercadorias, a colonização acrescentou o caráter produtivo, principalmente no continente americano. A criação do pacto colonial garantiu o monopólio comercial e a posse de terras para a metrópole.

No século XVI, a produção de açúcar passou do Oriente para o Atlântico Oriental, graças aos portugueses, que a introduziram em Cabo Verde, São Tomé, Madeira, Açores, etc. A seguir, o Brasil passou a produzir açúcar e, a partir do século XVII, a agricultura açucareira entrou em decadência nas ilhas do Atlântico, devido ao dinamismo do açúcar brasileiro no mercado mundial. ${ }^{2}$

Inicialmente, a utilização da mão-de-obra escrava para trabalhar nos engenhos foi ameríndia. Entretanto, o baixo estágio cultural em que se encontravam, associado à rápida redução do contingente (maus tratos e doenças) fizeram com que, a partir do início do século XVII, a mão-de-obra negra se tornasse hegemônica. ${ }^{3}$ 
Em se tratando do Brasil, a escravidão foi tão determinante que: "Ao invés de modo de produção secundário e periférico, qual o das ilhas atlânticas portuguesas, o escravismo, ao se prender à colonização do Brasil, adquiriu a natureza de modo de produção dominante, em escala imensamente superior, servindo de base a uma formação social historicamente nova."

Até meados do século XIX, o desenvolvimento da agricultura canavieira no nordeste do Brasil ensejou o surgimento de um fluxo sistemático de cativos vindos da África. A obtenção de escravos africanos era tão importante que, segundo o padre Antônio Vieira, sem negros não haveria Pernambuco, e sem Angola, não haveria negros. ${ }^{5}$

É certo que o primeiro objetivo dos portugueses foi a procura de metais preciosos. À medida que o açúcar ia determinando os rumos da economia colonial, os interesses na África adquiriam outro caráter. A aquisição de homens escravizados no continente negro levou os portugueses a criarem toda uma infra-estrutura administrativa, militar e diplomática. A presença portuguesa na costa ocidental africana remonta à segunda metade do século XV. Em 1482, Diogo Cão chegou à foz do rio Zaire e estabeleceu contato com o reino do Congo. ${ }^{6}$

Segundo Robert Conrad, o crescimento do comércio de escravos para o Brasil está relacionado a dois fatores: "[...] a oportunidade econômica combinada com um devastador sistema de administração humana que não permitia o crescimento natural da população escrava no Brasil. ${ }^{7}$ Esses fatores foram uma consequêencia da busca do lucro rápido e da facilidade de reposição da mão-de-obra.

As estimativas quanto ao número de cativos introduzidos no Brasil são variadas. Segundo Maurício Goulart: "Não é fácil; ao contrário, uma série quase ininterrupta de dificuldades, a avaliação do volume do tráfico africano para o Brasil. Não há estatísticas precisas, escreve Calógeras, os arquivos desapareceram, e, assim, nada se pode afirmar de positivo." Apesar das diversidades, os historiadores que se dedicam ao assunto possibilitam uma base relativamente segura. Frédéric Mauro afirma que, na primeira metade do século XVII, entraram cerca de 200.000 negros no Brasil. Isto daria um ingresso de 4.000 por ano. ${ }^{9}$

Entre os trabalhos referentes a presença portuguesa na África, mais notadamente em Angola, destaca-se a História Geral das Guerras Angolanas, concluída por Antônio de Oliveira de Cadornega, em 1681. A 
obra abrange até finais do século XVII. Nela, Cadornega descreve de forma épica as administrações dos governadores-gerais em Angola. As diversas provações a que foram submetidos os portugueses ou a que eles submeteram os povos angolanos mostram a importância que o território tinha para a Coroa. Assim, produzida no contexto do século XVII, a obra de Antônio de Oliveira de Cadornega representa uma fonte primária de consulta obrigatória para os estudiosos do assunto. Utilizando-a como tal, procuraremos destacar as referências feitas sobre o comércio de escravos em Angola.

Cadornega foi para Angola acompanhando o governador Pedro Cezar de Menezes, em $1639 .{ }^{10}$ Seguiu carreira militar e obteve patente de capitão em 1649 concedida pelo então governador Salvador Correia de Sá e Benevides. ${ }^{11}$ Cadornega ficou vinte e oito anos em Massangano onde, em 1660, foi Juiz Ordinário. Criou a Santa Casa de Misericórdia tendo sido seu primeiro Provedor. Em 1671, foi vereador em Luanda, e morreu em $1690 .^{12}$

Desde o momento em que o comércio de escravos tornou-se um negócio rendoso, a Coroa portuguesa procurou meios de tirar proveito. Entre as medidas tomadas, foram criados os "Contratos de Assento", que regulamentavam o comércio de cativos na África e no Brasil. ${ }^{13}$

Quando o reino do Congo foi descoberto, D. João II reinava em Portugal. Charles Boxer relata a característica inicial da conquista portuguesa nesta região: "O rei D. João II de Portugal e seus sucessores da Casa de Aviz não tentaram assegurar o controle político deste reino, tampouco procuraram conquistá-lo pela força das armas. Contentavam-se em reconhecer os reis do Congo como seus irmãos de armas; em tratá-los como aliados e não como vassalos; e convertê-los e a seus súditos ao cristianismo, enviando missionários ao Congo e educando jovens congoleses selecionados no mosteiro de Santo Elói e noutros lugares, em Lisboa." 14

A diplomacia utilizada pelos portugueses com os africanos do Congo não se aplicou a todos os povos por eles conquistados, mas $\operatorname{sim}$ fez parte de uma estratégia de dominação. Ela refletiu, no caso dos povos de Angola, o fato de terem encontrado sociedades culturalmente bem estruturadas. $\mathrm{O}$ verdadeiro exemplo do pensamento português acha-se explícito na opinião de Cadornega: [...] porque este gentio não se doma a nada por afagos nem boas razōes se não com o temor e respeito[...]." 15 
Ao final do século XVI, Congo e Ndongo representavam os principais mercados fornecedores de escravos na África Ocidental. ${ }^{16} \mathrm{~A}$ compra de escravos processou-se de duas maneiras: a negociação com os sobas através do escambo ou simplesmente o ataque a aldeias. A primeira forma foi a mais utilizada, porque introduziu um caráter novo às presas de guerras inter-aldeãs e outras formas.

A colonização de Angola foi uma iniciativa de Paulo Dias de Novais ${ }^{17}$ que, em 1575 , fundou a cidade de Luanda. A partir daí, a ocupação deu-se de forma sistemática. No interior do território, surgiram núcleos de povoaçâo denominados "presídios" ou "fortalezas". ${ }^{18}$ O escravo passou a ser a mercadoria mais procurada pelos comerciantes e mais oferecida pelos sobas. Um papel de destaque era dado aos "pumbeiros". Eles eram, às vezes, "escravos" de colonos portugueses e iam ao interior para negociar com os sobas. A designação "pumbeiro" originou-se de Mbanza Mpumbo, capital da província de Nsundi, no reino do Congo. O mercado onde se adquiria cativos denominava-se "pumbo". Os "pumbeiros" dividiam-se em "descalços" (que atuavam no interior) e "calçados" (mais ricos e urbanos). ${ }^{19}$

Sobre a atuação dos pumbeiros, Cadornega comentava: "É porque se entenda a oppulencia de peças e commércio que havia neste Reino de Angola como ainda hoje ha, mas não em tanta abundancia, que ha muitos annos se tira agoa desta fonte, no Sertão e nos quilombos guerras de mais proveito do que as de hoje, hião muitos negros mercadores ou commerciantes chamados Pombeiros com muita fazenda Banzada ${ }^{20}$ de seus senhores, afunar ${ }^{21}$ peças, e erão tão dextros nisto que se prezavão de fazer aquelle negócio[...].".22

Em Angola, o comércio de escravos não se desenvolveu de forma pacífica. Os portugueses encontraram muita resistência por parte dos nativos. Essa resistência, entretanto, não teve o mesmo caráter daquela efetuada pelos escravos no Brasil. Ela foi, antes de mais nada, uma luta por questões de soberania. Embora a Coroa portuguesa tenha feito alianças com alguns sobas, sempre houve a necessidade do emprego da força contra aqueles que se negavam a reconhecer a autoridade portuguesa. Um dos exemplos ocorreu durante o governo de Fernão de Souza ${ }^{23}$ e é descrito por Cadornega: "A primeira empreza em que se ocupou foi em ir contra os Sovas da Província do Lumbo que impedirão a 
feira Real de peças que era couza naquelle tempo de mui importância ao commércio[...]". ${ }^{24}$

Os conflitos entre portugueses e nativos foram mais acentuados com relação aos jagas. Há muitas conjecturas a respeito da origem deste grupo. Segundo Silva Rego: "Ainda hoje se discute a sua origem e a data exacta de seu súbito aparecimento na África Central e Austral. Segundo uns, teriam vindo do território que se estende das nascentes do Nilo às do Congo. Segundo outros, teriam seu berço nas cordilheiras da região da Serra Leoa." 25 É certo que eles invadiram o reino do Congo, no tempo do manicongo "D. Afonso I". Calcula-se que este último tenha começado a reinar depois de $1566 .{ }^{26}$ Os jagas atuaram, às vezes, como aliados dos portugueses e, outras, como opositores. Com eles, o comércio de escravos intensificou-se pois possuíam muitas presas de guerra.

No governo de Bartolomeu de Vasconcelos da Cunha, ${ }^{27}$ chegou a Luanda uma nau espanhola com prata e piroleiras ${ }^{28}$ de vinho de Sevilha. Segundo Cadornega, esta era a mercadoria mais usada nos pumbos e resgates. Os espanhóis negociavam com os jagas, "e no poderoso reino de Casanji de cujos resgates vem as melhores peças de Escravos por serem mui amigos deste licor e são tâo seus affeiçoados, que quando não tem Gentio apanhado em suas guerras, para fazerem emprego, vendem dos de seu serviço já Domésticos só para beberem[...]".29

Os jagas sabiam da importância que os escravos tinham para os portugueses. A cada ida aos seus quilombos, o preço da peça sempre estava alterado. Por essa razão, o governo de Angola instruiu os comerciantes a não aceitarem os aumentos de preços para não incentivar esta prática. ${ }^{30}$

A ocupação de Luanda pelos holandeses, em 1641, representou um duro golpe para os lusitanos. Esta invasão fez com que o governador Pedro Cezar de Menezes se retirasse para o interior e instalasse a administração, primeiro na fortaleza de Muxima e, logo após, em Massangano. A resistência à dominação holandesa, no Brasil e Angola, foi mais um empreendimento dos próprios colonos do que da Coroa portuguesa. Durante o período de ocupação, o comércio de escravos continuou. Os holandeses fizeram acordos com alguns sobas, garantindo assim o fornecimento de peças. A situação de guerra alterou o preço do escravo no Brasil. Em 1644, o preço de uma peça subiu de 20.000 para 80.000 reais. $^{31}$ 
A situação de penúria em que ficaram os portugueses em Angola chegou a tal ponto, que muitos deles atacavam os quilombos dos jagas para capturarem escravos e trocarem com os holandeses por roupa e comida. $^{32}$

Os holandeses foram expulsos de Angola em 1648. A expedição foi financiada e organizada no Brasil a pedido do Conselho Ultramarino: "[...] porque faltava Fazenda Real para abastecer, e ser jornada tão prolongada, pedio hum empréstimo aos moradores de mais posses daquella cidade de São Sebastião [Rio de Janeiro] de sesenta mil cruzados, ou os que forão, os quaes todos derão o que tocou de repartição com grandissima vontade pois era serviço del Rey, e em utilidade de todas as Praças do Brasil a restaurar-se Angola a respeito do Commércio de Escravos para a fábrica dos Engenhos de Assucar e mais serviço daquelle Estado, de que estavão mui faltos [...]." ${ }^{33}$

Após a expulsão dos holandeses, o governo de Angola foi entregue a Salvador Correia de Sá e Benevides. Sua primeira atitude foi organizar o comércio de escravos e seu tráfico para o Brasil. Um exemplo, foi o combate aos sobas na província do Libolo porque impediam o comércio dos pombeiros. ${ }^{34}$ Durante seu governo, foi freqüente o envio de negros para a região do Prata, apesar de ser considerado ilegal pelas autoridades portuguesas. O comércio clandestino efetuado pelos portugueses na América espanhola, foi motivo de muitas reclamações por parte dos comerciantes. $^{35}$ Nesta região, as áreas receptoras de escravos foram principalmente Tucumán e Buenos Aires. Destes locais, uma parte seguia para Potosí. ${ }^{36}$ Sobre a presença de estrangeiros em Angola, Cadornega relata: "Há muitos homens de negócio, huns que estão de assento e outros que fazem suas viagens, alguns delles de grosso cabedal, muita produção, e gente marítima que vem em navios ao trato de negócio das peças; e se achão continuamente no porto desta cidade passante de vinte navios [...]."37

Justificava-se a preocupação do Conselho Ultramarino porque a presença de estrangeiros em Angola trazia prejuízos à Fazenda Real.

O Contratador era o encarregado de arrecadar os direitos sobre o comércio de escravos em nome da Coroa. Até 1650, cada peça exportada custava dois tostões. Com isto, a Fazenda Real chegava a arrecadar de 5 a 6.000 cruzados por ano. Segundo Frédéric Mauro, os "escravos que entram no Brasil também pagam direitos, variáveis segundo os portos e as 
épocas. Em 1624 o conjunto dos direitos percebidos pelo contratador eleva-se a 4.000 réis por peça". ${ }^{38}$

O têrmo 'peça' não era necessariamente um sinônimo de escravo. Para se completar uma peça, às vezes eram necessários dois ou três escravos. Segundo F. Mauro: "A peça representa um negro de 15 a 25 anos. Um negro de 8 a 15 anos (molecão) ou de 25 a 35 anos não constitui uma peça inteira; são precisos três para fazer duas peças. As crianças com menos de 8 anos (moleques) e os adultos de 35 a 45 anos contam 1/2 peça. As crianças de peito seguem as mães e não contam. Os doentes e os que têm mais de 45 anos são julgados por árbitros. O escravo ideal é a peça de $1,82 \mathrm{~m}$, de 25 anos e sem defeitos físicos. Abaixo de 1,65m, uma peça perde muito de seu valor." 39

Os impostos criados pela metrópole em relação ao comércio de escravos geraram protestos por parte dos traficantes, porque a mercadoria tornou-se cada vez mais cara. Um exemplo dessas reclamações ocorreu durante o governo de André Vidal de Negreiros ${ }^{40}$ em Angola: "[...] e vierão a conferir que sem embargo que as peças de Escravos tinhão muita carga sobre sy que era quatro mil Réis de direitos Reais antigos, três de direito novo que erão sete, quatro de costeamento para o sustento de cada cabeça de mar e terra que vinhão a ser onze, não achavão outro meio de por mais mil Réis em cada cabeça de Escravo, que fazião doze, que vinha as ser meyo por meyo do que valia huma peça de Índias ${ }^{41}$ desta cidade $[\ldots] .{ }^{42}$

O comércio de escravos entre África e Brasil durou mais de três séculos. Se no continente africano ele representou a destruição de antigas formações sociais, no Brasil, foi parte integrante na construção de um novo modo de produção, o escravista colonial, com características próprias. Para Jacob Gorender: "Seu surgimento não encontra explicação nas direções unilaterais do evolucionismo nem do difusionismo. Não que o escravismo colonial fosse invenção arbitrária fora de qualquer condicionamento histórico. Bem ao contrário, o escravismo colonial surgiu e se desenvolveu dentro de determinismo sócio-econômico rigorosamente definido, no tempo e no espaço. Deste determinismo de fatores complexos, precisamente, é que o escravismo colonial emergiu como um modo de produção de características novas, antes desconhecidas na história humana., ${ }^{\prime 3}$ 
O escravismo foi um elemento determinante para o desenvolvimento do Brasil e também de alguns países europeus. Em se tratando do Brasil, ele esteve ligado à implantação de uma economia agroexportadora. O tráfico negreiro adquiriu tamanha importância, que para seu bom andamento foi criada toda uma infra-estrutura não só nas áreas fornecedoras, mas nas receptoras de escravos. Um exemplo é o Contrato de Assento.

Os portugueses foram os mais interessados e praticantes do tráfico pela dependência existente entre sua economia e o comércio do açúcar brasileiro.

\section{Conclusão}

Procuramos demonstrar a prática do comércio de escravos em Angola na visão de alguém que a presenciou. A obra de Cadornega não é uma narrativa do comércio negreiro em Angola. Nela podemos vislumbrar, com riqueza de detalhes, o caráter conquistador do povo português no território angolano desde a descoberta do reino Congo até o ano de 1681. As descrições da política adotada por cada governadorgeral estão associadas a uma riqueza imensa de informações a respeito dos povos de Angola e suas relações com os portugueses. Ao utilizarmos História Geral das Guerras Angolanas como fonte historiográfica, tivemos a preocupação de entender o posicionamento do autor enquanto testemunha ocular. Caso contrário, estaríamos incorrendo em um anacronismo. 


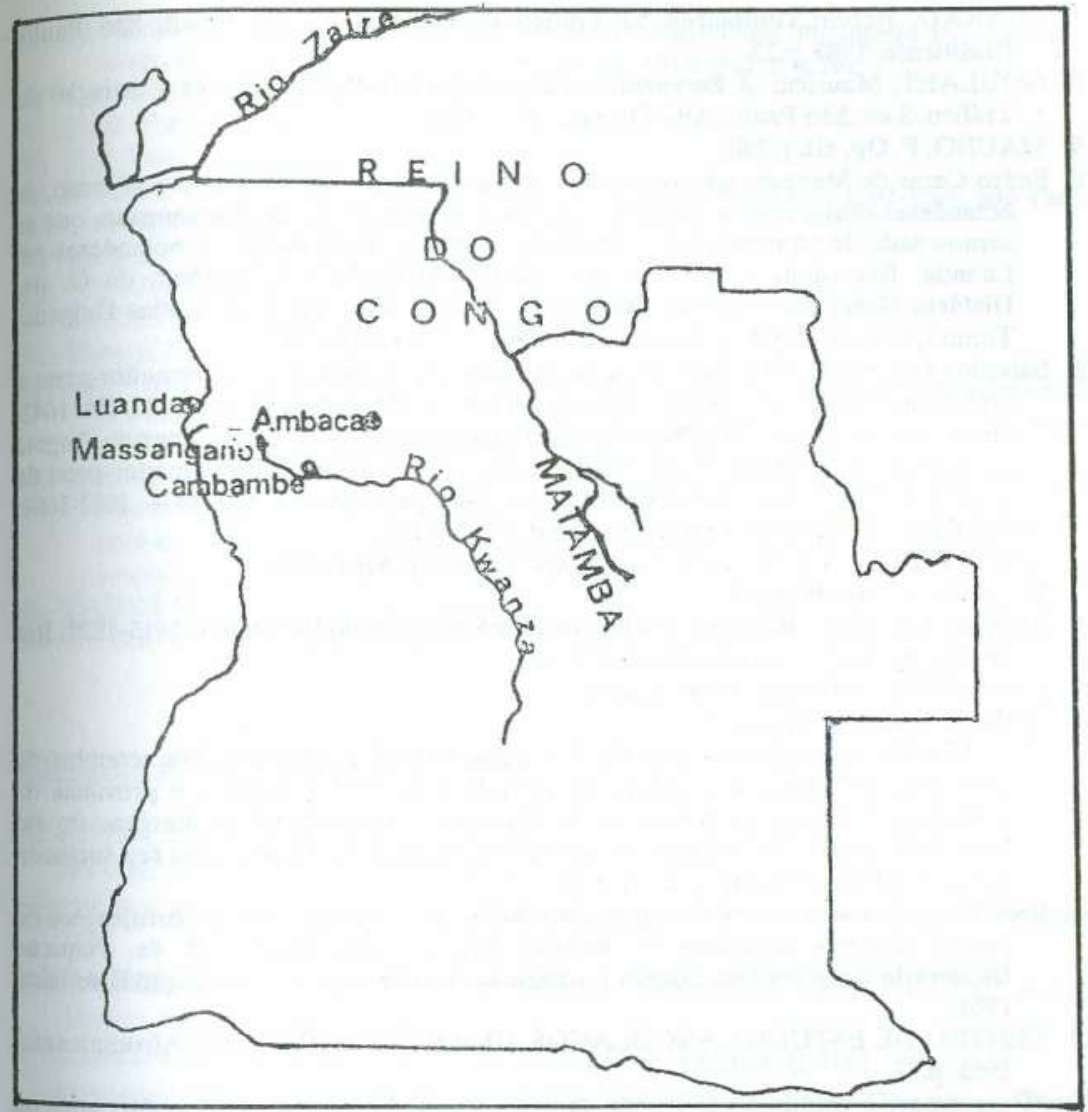

Mapa de Angola no Século XVII

\section{Notas}

1. FENELON, Dea Ribeiro. 50 Textos de História do Brasil. São Paulo, Hucitec, 1974. v.2. p.26.

2. MAURO, Frédéric. Portugal, o Brasil e o Atlântico (1750-1670). Lisboa, Estampa, 1989. p.243.

3. BOXER, C.R. O Império Colonial Português (1415-1825). Lisboa, Ediçz̃es 70, 1981. p.102.

4. GORENDER, Jacob. O Escravısmo Colonlal. 3.ed. Săo Paulo, Ática, 1980. p.145.

5. Apud RODRIGUES, José H. Brasil e África: Outro Horizonte. 3.ed. Rio de Janeiro, Nova Fronteira, 1982. p.46.

6. BENDER, Gerald J. Angola: Mito y Realidad de su Colonización. México, Siglo Veintiuno, 1980. p.39. 
7. CONRAD, Robert.Tumbeiros. O Tráfico de escravos para o Brasil. São Paulo, Brasiliense, 1985. p.15.

8. GOULART, Maurício. A Escravidão Africana no Brasil: Das origens à extinção do Tráfico. 3.ed. Săo Paulo, Alfa-Omega, 1975. p.96.

9. MAURO, F. Op. cit. p.240.

10. Pedro Cezar de Menezes governou Angola inicialmente em 1639. Em seu governo, os holandeses obrigaram os colonos lusitanos a se refugiarem em Massangano, que se tornou sede da administração portuguesa. Menezes foi preso pelos holandeses em Luanda. Reassumiu o governo, em 1644. CADORNEGA, Antônio de O. de. História Geral das Guerras Angolanas. Anot. e Cor. por José Matias Delgado, Tomo I, Lisboa, Agência Geral do Ultramar, 1972. p.197 e 343.

11. Salvador Correia de Sá e Benevides foi nomeado, primeiramente, governador-geral e capitão-mor do Rio de Janeiro por um decreto do Rei Felipe IV, em 1636. Em 1643, obteve um cargo no Conselho Ultramarino. Comandou a frota que libertou Angola do domínio holandês em 1648. Neste mesmo ano, foi nomeado governador-geral de Angola. BOXER, C.R. Salvador de Sa e a Luta pelo Brasil e Angola - 1602-1686. São Paulo, Companhia Editora Nacional, 1973. p.125.

12. CADORNEGA, Antonio de O. de. Op. cit. Tomo I. p.XII e XIII.

13. MAURO, F. Op. cit. p.213.

14. BOXER, Charles R. Relaçöes Raciais no Império Colonial Português: 1415-1825. Rio de Janeiro, Tempo Brasileiro, 1967. p.53.

15. CADORNEGA. Op. cit. Tomo I, p.53.

16. BOXER, C.R. Op. cit. p.108.

17. Paulo Dias de Novais recebeu patente de conquistador de Angola em 19 de setembro de 1571. Em 1575 fundou a cidade de Luanda. Em 1580, submeteu a província da Quissama e fundou as fortalezas de Muxima e Massangano às margens do rio Kuanza. Paulo D. Novais morreu em 1589 e deixou Luíz Serăo como seu sucessor. CADORNEGA. Op. cit. Tomo I, p.18.

18. Presídios e fortalezas eram denominações dadas pelos portugueses às fortificaçōes ou praças militares instaladas no interior. HOLANDA, Aurélio B. de. Pequeno Dicionário Brasileiro da Língua Portuguesa. Rio de Janeiro, Civilizaçăo Brasileira, 1961.

19. CENTRO DE ESTUDOS ANGOLANOS. História de Angola. Porto, Afrontamento, 1965. p.77.

20. "Banzada era o computo que havião de dar por cada Escravo a que chamão banzo ou banzos". CADORNEGA. Op. cit. Tomo I, p.143.

21. "Funar he comprar e mercanciar". CADORNEGA. Op. cit. Tomo I, p.143.

22. Id. ibid.

23. Fernăo de Souza foi governador de Angola a partir de 1625 . Uma preocupação de sua administração foi incentivar a agricultura com o objetivo de acabar com a dependência de Angola em relação ao Brasil. CADORNEGA. Op. cit. Tomo I, p.124.

24. Idem. Tomo I, p.77.

25. REGO, Antonio da Silva. A Dupla Restauraçăo de Angola. 1641-1648. Lisboa, Agência Geral das Colônias, 1948. p.10.

26. CADORNEGA. Op. cit. Tomo I, p.12.

27. Bartolomeu de Vasconcelos da Cunha foi governador de Angola entre 1653 e 1654 . Substituiu seu irmão, Francisco de Vasconcelos da Cunha. Cadornega e outros autores consultados afirmam que ele năo realizou nenhuma obra enquanto esteve no governo. CADORNEGA. Op. cit. Tomo I, p.521.

28. Piroleira ou peroleira: "Vasilha afunilada para guardar azeitonas". HOLANDA, Aurélio B. de. Op. cit. p.923.

29. CADORNEGA,. A. de O. Op. cit. Tomo II, p.80.

30. Idem. p.257. 
31. ALMEIDA, Pedro Ramos de. História do Colonialismo Português em África. Cron. Séc. XV-Séc. XVIII. Lisboa, Estampa, 1978. Vol. I, p.291.

32. CADORNEGA. Op. cit. Tomo I, p.344.

33. Idem. Tomo II, p.2.

34. Ibid. Tomo II, p.43.

35. BOXER, C.R Salvador de Sá e a Luta pelo Brasil e Angola - 1602-1686. São Paulo, Companhia Editora Nacional, 1973. p.93.

36. Idem. p.238.

37. CADORNEGA. Op. cit. Tomo III, p.31.

38. MAURO, F. Op. cit. p.225.

39. Idem. p.232.

40. André Vidal de Negreiros governou Angola entre 1661 e 1666. Seu governo foi marcado por muitas violências, inclusive foi acusado de degredar angolanos para Pernambuco. ALMEIDA, Pedro R. de. Op. cit. p.319.

41. "Peça-de-Índia definia o escravo jovem, alto, robusto e sem defeitos físicos. Em época adiantada do tráfico, usou-se a bitola de $1,75 \mathrm{~m}$ de estatura para designar a peça-de-Índia." CARRERA, Antonio. Notas sobre o Tráfico Português de Escravos. Lisboa, Universidade Nova Lisboa, 1978. p.62.

42. CADORNEGA, A. de O. de. Op. cit. p.199.

43. GORENDER, Jacob. Op. cit. p.54.

\section{Bibliografia}

ALMEIDA, Pedro Ramos de. História do Colonialismo Português em África. Cron. Séc. XV-Séc. XVIII. Lisboa, Estampa, 1978. Vol. I.

BENDER, Gerald J. Angola: Mito y Realidad de Su Colonización. México, Siglo Veintiuno, 1980.

BOXER, Charles R. Relaçōes Raciais no Império Colonial Português. 1415-1825. Rio đe Janeiro, Tempo Brasileiro, 1967.

-. O Império Colonial Português. (1415-1825). Lisboa, Edições 70, 1981.

-. Salvador de Sá e a Luta pelo Brasil e Angola. 1602-1686. São Paulo, Companhia Editora Nacional, 1973.

CADORNEGA, Antonio de Oliveira de. História Geral das Guerras Angolanas. Anot. e Cor. por José Matias Delgado. Lisboa, Agência Geral do Ultramar, 1972. 3 tomos.

CENTRO DE ESTUDOS ANGOLANOS. História de Angola. Porto, Afrontamento, 1965.

CONRAD, Robert. Tumbeiros. O Tráfico de escravos para o Brasil. Săo Paulo, Brasiliense, 1985.

FENELON, Dea Ribeiro. 50 Textos de História do Brasil. São Paulo, Hucitec, 1974. Vol. 2.

GORENDER, Jacob. O Escravismo Colonial. 3.ed. Săo Paulo, Ática, 1980.

GOULART, Maurício. A Escravidão Africana no Brasil. Das origens à extinção đo Tráfico. 3.ed. São Paulo, Alfa-Omega, 1975.

HOLLANDA, Aurélio B. Pequeno Dicionário Brasileiro da Língua Portuguesa. Rio de Janeiro, Civilizaçăo Brasileira, 1961.

MAURO, Frédéric. Portugal, o Brasil e o Atlântico. (1570-1670). Lisboa, Estampa, 1989.

REGO, Antonio da Silva. A Dupla Restauraçäo de Angola. 1641-1648. Lisboa, Agência Geral do Ultramar, 1948. 